Original Research Article

\title{
Dose-dependent analgesic activity of mexiletine on thermally induced pain in rats
}

\author{
Aravind Patil ${ }^{1}$, Vijaya Chandra Reddy Konda ${ }^{2 *}$
}

\begin{abstract}
${ }^{1}$ Medical Scientific Liaison, Medical Affairs, Bangalore, Karnataka, India

${ }^{2}$ Department of Pharmacology, Sri Venkateswara Institute of Medical Sciences, Sri Padmavathi Medical College for Women, Tirupati, Andhra Pradesh, India
\end{abstract}

Received: 16 November 2018 Accepted: 26 November 2018

\section{*Correspondence to: \\ Dr. Vijaya Chandra Reddy Konda, \\ Email: vijayachandrareddy@ gmail.com}

Copyright: (C) the author(s), publisher and licensee Medip Academy. This is an openaccess article distributed under the terms of the Creative Commons Attribution NonCommercial License, which permits unrestricted noncommercial use, distribution, and reproduction in any medium, provided the original work is properly cited.

\begin{abstract}
Background: Pain is an unpleasant sensory and emotional experience associated with actual or potential tissue damage or described in terms of such damage. In spite of many advances in pain research, we are unable to deal in an effective way. The cost for new drug development is increasing day by day. Drug repurposing is an approach to look for new use in drugs that are already approved for other indications. Mexiletine is a sodium channel blockers that is being approved for treatment of arrhythmias. It is being tried in treatment of various painful conditions. The present study is to evaluate the dose-dependent analgesic activity of mexiletine with ibuprofen.

Methods: The analgesic activity of mexiletine was compared at doses of $15 \mathrm{mg} / \mathrm{kg}, 30 \mathrm{mg} / \mathrm{kg}$ and $45 \mathrm{mg} / \mathrm{kg}$ with the standard dose of ibuprofen at $10 \mathrm{mg} / \mathrm{kg}$ in male Wistar rats in thermal model of tail flick analgesiometer.

Results: At lower doses $(15 \mathrm{mg} / \mathrm{kg})$ of mexiletine, analgesic activity of ibuprofen was significantly higher. At higher doses $(30 \mathrm{mg} / \mathrm{kg}$ and $45 \mathrm{mg} / \mathrm{kg})$ of mexiletine, it was observed that there is no significant difference between the analgesic activities of both drugs.

Conclusions: Mexiletine demonstrated a dose-dependent analgesic activity. There was no statistically significant difference between the analgesic activities of higher doses of mexiletine when compared to ibuprofen.
\end{abstract}

Keywords: Analgesia, Analgesiometer, Ibuprofen, Mexiletine, Tail flick

\section{INTRODUCTION}

Pain is defined as 'an unpleasant sensory and emotional experience associated with actual or potential tissue damage or described in terms of such damage'. ${ }^{1}$ Nonopioid analgesics such as salicylates, paracetamol and NSAIDs; opioids; and other drug classes that include antidepressants and anticonvulsants are used either alone or in combination in treatment of various types of pain. In addition, it is established that drugs acting through the modulation of movement of ions through voltage-gated ion channels are increasingly being used as analgesic agents. ${ }^{2}$ Development of anti-nerve growth factor and antitransient receptor potential vanilloid 1 (anti-TRPV1) based therapies are still under clinical development, as there is lack of conclusive evidence for their safety and efficacy.

In spite of decades of pain research, it is stated that the approaches to treat pain is inadequate and inequitable. 
Further, trends observed indicate that research and development efforts for newer medicines for pain are declining. ${ }^{2}$ This is due to high cost involved in the development of newer drugs. ${ }^{5}$ Drug repurposing is an approach, where existing licensed drugs are being used for new medical indications, thereby potentially reducing the costs involved in drug development. ${ }^{6}$ It is recently observed that drugs like minocycline, ceftriaxone, pioglitazone and sivelestat have demonstrated analgesic activity. $^{7}$

Studies have shown that expression and functional properties of voltage-gated sodium channels are regulated after axonal injury or peripheral inflammation in sensory neurons. ${ }^{8}$ Mexiletine is a voltage-gated sodium channel (VGSC) blocker, classified as a class 1B antiarrhythmic in the Vaughan-Williams classification scheme of antiarrhythmic drugs. ${ }^{9}$ It acts by binding preferentially to the open and/or inactivated states of the channels. It exhibits use-dependent blockade of sodium channels on pathologically hyperactive tissues. ${ }^{10}$ The family of VGSCs is linked to neuronal and cardiac disorders. These sodium channels blockers are clinically used as anticonvulsants, local anaesthetics and anti-arrhythmics. Mexiletine also has a role in peripheral neuropathy and chronic pain. ${ }^{11-13}$ Recently, it has been used in the treatment of sporadic amyotrophic lateral sclerosis. ${ }^{14}$

Mexiletine has been used off-label for various painful conditions of chronic nature. It's use as an analgesic agent is yet not well established. Though the major limitation for its routine use is the incidence of adverse effects, a recent study demonstrated that mexiletine is safe at both $300 \mathrm{mg}$ and $900 \mathrm{mg}$ doses per day in humans and is well tolerated at lower doses. ${ }^{14}$ In view of the increasing cost of new drug development and considering a drug repurposing approach, we planned to study the dose dependent analgesic activity of mexiletine in animal models. Further, number of studies demonstrating the analgesic activity of mexiletine in animal models are meagre. As it is a preliminary study, it was planned to study in a thermal model of tail flick by using analgesiometer, in comparison to ibuprofen as the standard drug.

\section{METHODS}

All the animals included in the study were procured from animal house of Dr. Pinnamaneni Siddhartha Institute of Medical Sciences, Chinnoutpalli, Andhra Pradesh, India. Male Wistar rats weighing between 200-250grams were used in the study. The animals are housed in poly propylene cages under similar environmental conditions and strict aseptic conditions throughout the experiment. The animals were maintained under standard laboratory conditions at $25^{\circ} \mathrm{C}$ and have access to commercial pellet diet with water ad libitum, and normal photo period (12h dark/12h light) was strictly followed. The protocol was approved by the Institutional Animal Ethics Committee (IAEC) before the start of the study.

\section{Drugs and chemicals}

Mexiletine (German Remedies Private Limited.), Ibuprofen (Nestor Pharmaceuticals Limited), distilled water and normal saline were used in this study.

\section{Instruments}

Tail flick Digital Analgesiometer - Inco, Ambala, India.

Animal dose calculation from human dose $\mathrm{e}^{15,16}$

Animal dose=Human effective dose (mg/kg) x $\underline{\text { Human } \mathrm{Km}}$ Animal Km

\section{Doses of drugs used}

Normal saline- $0.2 \mathrm{ml}$ orally, mexiletine - according to body weight orally. (15mg/kg, 30mg/kg, and $45 \mathrm{mg} / \mathrm{kg}$ ), and Ibuprofen - according to body weight orally (10mg/kg.)

\section{Experimental design and treatment}

A total of 30 male Wistar rats weighing 200 to 250 grams were divided into five groups of six rats each after physical randomization. Group 1 was control and received normal saline; group 2 was standard and received ibuprofen $10 \mathrm{mg} / \mathrm{kg}$; groups 3,4 and 5 received $15 \mathrm{mg} / \mathrm{kg}, 30 \mathrm{mg} / \mathrm{kg}$ and $45 \mathrm{mg} / \mathrm{kg}$ of mexiletine respectively. All the drugs were given orally. Evaluation of analgesic activity was done by tail flick method by digital analgesiometer. ${ }^{17}$ Mean values of all the data were tabulated and statistical analysis was performed.

\section{Tail flick analgesiometer}

Effect of the test drug was obtained in terms of tail flick latency period using an analgesiometer at 30minutes, 60 minutes and 90minutes after administration of the drugs. The instrument was operated at $2.5 \mathrm{amps}$ current throughout the experiment. Rat was placed in the metallic rate holder and the tail of the rat was placed on the groove with for holding the tail above the heater wire. Radiant heat was directed to the proximal third of the tail through a hot wire of the analgesiometer and the reaction time was noted.

A cut off period of 10 seconds was observed to prevent damage to the tail. Any animal failing to withdraw its tail within the cut off period was not used in the study. The cut off time was considered as the latency period for the animals not responding up to 10 seconds. The results were noted initially before giving the drug i.e. at 0 minutes; and then at 30minutes, 60minutes and 90minutes after administering the test and standard drugs. The normal reaction time (at 0 minutes) before the administration of the drug for each animal in all the groups, is the average of five readings taken at interval of 5 minutes before administration of drugs. 


\section{Statistical analysis}

The results were expressed as the mean \pm SEM (Standard Error of Mean). Statistical analysis was performed with one-way analysis of variance (ANOVA) for comparison of more than two groups followed by post hoc analysis using least significant difference (LSD). The $p$ value of $<0.05$ was considered statistically significant during the analysis of data.

\section{RESULTS}

The mean reaction times after exposing the rat's tail to radiant heat using analgesiometer at various time intervals are represented in Table 1. At baseline (time 0), there is no statistical difference $(\mathrm{p}>0.05)$ in mean reaction times in various groups when compared to control group.

Table 1: Mean reaction time of all the groups using tail flick analgesiometer.

\begin{tabular}{|c|c|c|c|c|}
\hline \multirow{2}{*}{ Group } & \multicolumn{4}{|c|}{ Reaction time in seconds at various time intervals } \\
\hline & o Minute & 30 Minutes & 60 Minutes & 90 Minutes \\
\hline Group 1 - control normal saline & $6.7 \pm 0.23$ & $6.6 \pm 0.33^{\#}$ & $7 \pm 0.36^{\#}$ & $7.1 \pm 0.30^{\#}$ \\
\hline Group 2 - standard ibuprofen $10 \mathrm{mg} / \mathrm{kg}$ & $6.6 \pm 0.04$ & $7.6 \pm 0.33^{*}$ & $7.8 \pm 0.22 *$ & $9.1 \pm 0.20^{*}$ \\
\hline Group 3 - test 1 mexiletine $15 \mathrm{mg} / \mathrm{kg}$ & $6.4 \pm 0.03$ & $6.6 \pm 0.21^{\#}$ & $7 \pm 0.36^{\#}$ & $8 \pm 0.36^{* \#}$ \\
\hline Group 4 - test 2 mexiletine $30 \mathrm{mg} / \mathrm{kg}$ & $6.5 \pm 0.04$ & $7 \pm 0.25$ & $7.6 \pm 0.33$ & $8.5 \pm 0.20^{*}$ \\
\hline Group 5 - test 3 mexiletine $45 \mathrm{mg} / \mathrm{kg}$ & $6.5 \pm 0.05$ & $7.3 \pm 0.30^{*}$ & $7.8 \pm 0.33^{*}$ & $9 \pm 0.36^{*}$ \\
\hline
\end{tabular}

All the values are expressed as Mean \pm SEM. ${ }^{*}$ p $<0.05$ when compared to control; ${ }^{*} \mathrm{p}<0.05$ when compared to standard

It was observed that there is an increase in mean reaction time of different groups from baseline to 90 minutes. The difference between the groups at different time intervals was found to be significant when analysed by one way ANOVA. In order to confirm where the difference occurred between groups, post hoc analysis of the data were done using least significant difference method (LSD).

As the study aimed at comparing the analgesic activity of mexiletine at different doses with ibuprofen as the standard drug, $\mathrm{p}$ values were compared between the groups in relation to standard group. It was observed that the mean reaction times in group 3 animals treated with $15 \mathrm{mg} / \mathrm{kg}$ of mexiletine was significantly lower than the standard group at 30minutes, 60minutes and 90minutes. There was no significant difference in mean reaction times observed among group $4(30 \mathrm{mg} / \mathrm{kg})$ and group $5(45 \mathrm{mg} / \mathrm{kg})$ when compared to standard group at all times after administration of drugs.

\section{DISCUSSION}

Mexiletine is an antiarrhythmic drug which is also being used in treatment of chronic painful conditions like neuropathy. The present study was done to evaluate the dose dependent analgesic activity of mexiletine at doses of $15 \mathrm{mg} / \mathrm{kg}, 30 \mathrm{mg} / \mathrm{kg}$ and $45 \mathrm{mg} / \mathrm{kg}$ in thermal pain model of tail flick analgesiometer by comparing it with ibuprofen at the dose of $10 \mathrm{mg} / \mathrm{kg}$.

The results of the analgesic activity revealed that there was an increase in reaction time with all the doses of mexiletine as seen with the standard drug ibuprofen. Findings as shown in Table 1, suggests that the mean increase in reaction time for standard drug was higher than for any dose of mexiletine at any time interval. When the data were further assessed for level of significance between the various groups, it was observed that only at low doses $(15 \mathrm{mg} / \mathrm{kg})$, there was a significant difference between mexiletine and ibuprofen.

Though the mean reaction times were higher for ibuprofen, it was observed that at higher doses with the test drug mexiletine $(30 \mathrm{mg} / \mathrm{kg}$ and $45 \mathrm{mg} / \mathrm{kg})$, there was no significant difference among the mean reaction times. These findings suggest that mexiletine has a dosedependent analgesic activity when compared to standard doses of ibuprofen.

The underlying mechanisms involved in analgesia by the two drugs are different. NSAIDs act by inhibition of prostaglandin synthesis. Mexiletine is a sodium channel blocker. It is an oral analogue of lidocaine. Study done by Olschewski et al, showed that lidocaine and mexiletine decreased the excitability of dorsal horn sensory neurons by inhibiting sodium and potassium currents in rats. ${ }^{18}$

In a study done by Laird JM et al, to evaluate the analgesic activity of use-dependent sodium channel blockers in mono-arthritic rats, it was observed that mexiletine was effective at reducing hyperalgesia of the inflamed joint. This effect was dose-dependent with a median effective dose of $30 \mathrm{mg} / \mathrm{kg} /$ day at all-time points of the study. ${ }^{19}$

In the present study, analgesic effect shown with mexiletine was also dose-dependent with maximum response seen with higher dose $(45 \mathrm{mg} / \mathrm{kg})$ than seen at lower doses $(15 \mathrm{mg} / \mathrm{kg}$ and $30 \mathrm{mg} / \mathrm{kg})$. 
It is observed for most of the drugs used for analgesia, there is increased response with increase in dose of drugs. ${ }^{20-23}$ Contrary to this, analgesic ceiling effect is the phenomenon that refers to the dose beyond which there is no additional analgesic effect. In a study comparing 400mg versus $600 \mathrm{mg}$ of ibuprofen in patients with postoperative dental pain conducted by Seymour and co-workers, showed that there is very little analgesic advantage to doses of ibuprofen above $400 \mathrm{mg}^{24}$ Till date no such analgesic ceiling effect was reported for mexiletine.

Side effects caused by mexiletine was one of the reasons for not considering this drug to be used routinely. A retrospective cohort study done by Romman A et al, regarding the tolerability of mexiletine in chronic pain clinic revealed that $23 \%$ of the patients discontinued mexiletine due to gastrointestinal or neurological side effects. All these side effects were mild and resolved with stoppage of mexiletine. ${ }^{12}$ A phase II trial conducted to evaluate the safety and tolerability of mexiletine with doses of $300 \mathrm{mg}$ per day and $900 \mathrm{mg}$ per day showed that mexiletine was safe at both the doses but was well tolerated only at $300 \mathrm{mg}$ per day dose. Adverse effects noted at doses of $900 \mathrm{mg}$ per day led to a higher rate of discontinuation. ${ }^{25}$ In order to overcome this, analogues of mexiletine were designed as alternatives which demonstrated better antiarrhythmic activity along with similar or less cardiovascular effects compared to mexiletine. These analogues have higher selectivity of action and fewer side effects. $^{26}$

As the new drug development cost is increasing and there is still need for newer analgesics for effective treatment of pain, these newer analogues can be considered for evaluation as analgesic agents. There is a need to compare the analgesic potential and tolerability of these analogues in various pain models in animals. Drug repurposing of these newer analogues of mexiletine which demonstrated antiarrhythmic activity with minimal side effects for analgesic activities can be a promising approach.

To authors' knowledge, this is the first study to compare the dose dependent analgesic activity of mexiletine with ibuprofen. The major limitation of the study is that it was conducted in only one thermal model of pain. Further studies are warranted to further evaluate the tolerability and activity of these higher doses compared to standard drugs. As newer analogues of mexiletine already demonstrated a favourable safety and efficacy profile in arrhythmia models, there is a need to further study those analogues in various pain models.

\section{ACKNOWLEDGEMENTS}

Authors would like to thank laboratory technicians and staff of the animal house of Dr. Pinnamaneni Siddhartha Institute of Medical Sciences and Research Foundation, Chinnoutpalli, Vijayawada, Andhra Pradesh, for their kind support in carrying on the study.
Funding: No funding sources

Conflict of interest: None declared

Ethical approval: The study was approved by the Institutional Animal Ethics Committee

\section{REFERENCES}

1. Merskey H, Bogduk N. Classification of Chronic Pain. 2nd ed. Seattle, WA:IASP Press;2004:207.

2. Wolkerstorfer A, Handler N, Buschmann H. New approaches to treating pain. Bioorg Med Chem Lett. 2016 Feb 15;26(4):1103-19.

3. Bannwarth B, Kostine M. Targeting nerve growth factor (NGF) for pain management: what does the future hold for NGF antagonists? Drugs. 2014 Apr;74(6):619-26.

4. Wong GY, Gavva NR. Therapeutic potential of vanilloid receptor TRPV1 agonists and antagonists as analgesics: Recent advances and setbacks. Brain Res Rev. 2009 Apr 1;60(1):267-77.

5. Workman P, Draetta GF, Schellens JH, Bernards R. How much longer will we put up with $\$ 100,000$ cancer drugs?. Cell. 2017 Feb 9;168(4):579-83.

6. Bertolini F, Sukhatme VP, Bouche G. Drug repurposing in oncology- patient and health systems opportunities. Nat Rev Clin Oncol. 2015 Dec;12(12):732-42.

7. Sisignano M, Parnham MJ, Geisslinger G. Drug Repurposing for the Development of Novel Analgesics. Trends Pharmacol Sci. 2016 Mar;37(3):172-83.

8. Cummins TR, Sheets PL, Waxman SG. The roles of sodium channels in nociception: implications for mechanisms of pain. Pain. 2007 Oct;131(3):243-57.

9. Kowey PR, Marinchak RA, Rials SJ, Bharucha DB. Classification and pharmacology of antiarrhythmic drugs. Am Heart J. 2000 Jul;140(1):12-20.

10. Camerino DC, Tricarico D, Desaphy JF. Ion channel pharmacology. Neurother J Am Soc Exp Neurother. 2007 Apr;4(2):184-98.

11. Challapalli V, Tremont-Lukats IW, McNicol ED, Lau J, Carr DB. Systemic administration of local anesthetic agents to relieve neuropathic pain. Cochrane Database Syst Rev. 2005 Oct 19;(4):CD003345.

12. Romman A, Salama-Hanna J, Dwivedi S. Mexiletine Usage in a Chronic Pain Clinic: Indications, Tolerability, and Side Effects. Pain Physician. 2018 Sep;21(5):E573-9.

13. Waxman SG, Merkies ISJ, Gerrits MM, Dib-Hajj SD, Lauria G, Cox JJ, et al. Sodium channel genes in painrelated disorders: phenotype-genotype associations and recommendations for clinical use. Lancet Neurol. 2014 Nov;13(11):1152-60.

14. Weiss M, Simmons Z, Atassi N, Graves M, Parziale $\mathrm{N}$, Salameh J, et al. A phase 2 study of mexiletine in sporadic amyotrophic lateral sclerosis (S50. 004). Neurol. 2015 Apr 6;84(14 Supplement):S50-004.

15. U.S. Department of Health and Human Services, Food and Drug Administration. Guidance for Industry: Estimating the Maximum Safe Starting Dose in Initial 
Clinical Trials for Therapeutics in Adult Healthy Volunteer. Center for Drug Evaluation and Research, Pharmacology and Toxicology; 2005. Available at: https://www.fda.gov/downloads/Drugs/Guidances/U CM078932.pdf\%23search=\%27guidekines+for+indu stry+sfe+starting\%27. Accessed 2 November 2018.

16. Nair AB, Jacob S. A simple practice guide for dose conversion between animals and human. J Basic Clin Pharm. 2016 Mar;7(2):27-31.

17. Vogel H, editor. Analgesic, Anti-inflammatory and Anti-pyretic activity. Drug Discovery and Evaluation: Pharmacological Assays. 3rd edition 2008. Berlin; New York:Springer;2007:983-1113.

18. Olschewski A, Schnoebel-Ehehalt R, Li Y, Tang B, Bräu ME, Wolff M. Mexiletine and lidocaine suppress the excitability of dorsal horn neurons. Anesth Analg. 2009 Jul;109(1):258-64.

19. Laird JM, Carter AJ, Grauert M, Cervero F. Analgesic activity of a novel use-dependent sodium channel blocker, crobenetine, in mono-arthritic rats. $\mathrm{Br} \mathrm{J}$ Pharmacol. 2001 Dec;134(8):1742-8.

20. Shaheed CA, Maher CG, Williams KA, Day R, McLachlan AJ. Efficacy, tolerability, and dosedependent effects of opioid analgesics for low back pain: a systematic review and meta-analysis. JAMA Intern Med. 2016 Jul 1;176(7):958-68.

21. Elhwuegi AS, Hassan KM. The analgesic effect of different antidepressants combined with aspirin on thermally induced pain in Albino mice. Libyan J Med. 2012;7.
22. Eljezi V, Biboulet C, Boby H, Schoeffler P, Pereira B, Duale C. The Dose-Dependent Effects of Ketoprofen on Dynamic Pain after Open Heart Surgery. Pain Physician. 2017;20(6):509-20.

23. Thürauf N, Fleischer WK, Liefhold J, Schmid O, Kobal G. Dose dependent time course of the analgesic effect of a sustained-release preparation of tramadol on experimental phasic and tonic pain. $\mathrm{Br} \mathrm{J}$ Clin Pharmacol. 1996 Feb;41(2):115-23.

24. Seymour RA, Ward-Booth P, Kelly PJ. Evaluation of different doses of soluble ibuprofen and ibuprofen tablets in postoperative dental pain. $\mathrm{Br} \mathrm{J}$ Oral Maxillofac Surg. 1996 Feb;34(1):110-4.

25. Weiss MD, Macklin EA, Simmons Z, Knox AS, Greenblatt DJ, Atassi N, et al. A randomized trial of mexiletine in ALS: Safety and effects on muscle cramps and progression. Neurology. 2016 Apr 19;86(16):1474-81.

26. Roselli M, Carocci A, Budriesi R, Micucci M, Toma M, Di Cesare Mannelli L, et al. Synthesis, antiarrhythmic activity, and toxicological evaluation of mexiletine analogues. Eur J Med Chem. 2016 Oct 4;121:300-7.

Cite this article as: Patil A, Konda VCR. Dosedependent analgesic activity of mexiletine on thermally induced pain in rats. Int J Basic Clin Pharmacol 2019;8:90-4. 